\title{
Developing a model to assess community- level risk of oral diseases for planning public dental services in Australia
}

\author{
Andrea M. de Silva ${ }^{1,2^{*}}$, Panagiota Gkolia ${ }^{3}$, Lauren Carpenter ${ }^{4}$ and Deborah Cole ${ }^{5}$
}

\begin{abstract}
Background: Poor oral health is a chronic condition that can be extremely costly to manage. In Australia, publicly funded dental services are provided to community members deemed to be eligible-those who are socio-economically disadvantaged or determined to be at higher risk of dental disease. Historically public dental services have nominally been allocated based on the size of the eligible population in a geographic area. This approach has been largely inadequate for reducing disparities in dental disease, primarily because the approach is treatment-focused, and oral health is influenced by a variety of interacting factors. This paper describes the developmental process of a multi-dimensional community-level risk assessment model, to profile a community's risk of poor oral health.

Methods: A search of the evidence base was conducted to identify robust frameworks for conceptualisation of risk factors and associated performance indicators. Government and other agency websites were also searched to identify publicly available data assets with items relevant to oral diseases. Data quality and analysis considerations were assessed for the use of mixed data sources.

Results: Several frameworks and associated indicator sets (twelve national and eight state-wide data collections with relevant indicators) were identified. Determination of the system inputs for the Model were primarily informed by the World Health Organisation's (WHO) operational model for an Integrated Oral Health-Chronic Disease Prevention System, and Australia's National Oral Health Plan 2004-2013. Data quality and access informed the final selection of indicators.

Conclusions: Despite limitations in the quality and regularity of data collections, there are numerous data sources available that provide the required data inputs for community-level risk assessment for oral health. Assessing risk in this way will enhance our ability to deliver appropriate public oral health care services and address the uneven distribution of oral disease across the social gradient.
\end{abstract}

Keywords: Dental, Health services, Planning, Data

\section{Background}

In Australia, publicly funded dental services are provided free or at little cost only to community members who are socio-economically disadvantaged, or at higher risk of developing dental disease for other reasons. The historical approach of allocating public dental services nominally on the size of the eligible population in a geographic region has been largely inadequate for reducing

\footnotetext{
* Correspondence: andreams@unimelb.edu.au

${ }^{1}$ Centre for Applied Oral Health Research, Dental Health Services Victoria, 720 Swanston Street, Carlton 3053, Australia

${ }^{2}$ Melbourne Dental School, University of Melbourne, Carlton 3053, Australia Full list of author information is available at the end of the article
}

disparities in dental disease. Further, the approach has generally focused on treatment needs rather than the causes of oral diseases, with the role of public dental services in disease prevention remaining under-developed. Oral health should also not be considered in isolation however, and to reduce the social gradient in the prevalence of dental disease, the underlying causes of ill health more broadly also need to be considered.

Whitehead identifies that health is influenced by individual lifestyle factors; social and community networks; living and working conditions; and socio-economic, cultural and environmental conditions [1]. The causes of 
social inequality in health are considered to be multiple and inter-related, which therefore requires that actions to address the issue must be interconnected across the different levels of influence. Further, the socio-ecological framework proposed by McLeroy et al. [2] identifies that numerous systems and contexts shape human development $[3,4]$. As such, the outcomes of both whole system, and more focussed interventions will depend upon factors operating at multiple levels. Points of intervention exist at the policy, community, organisational, interpersonal and intrapersonal levels [5].

There has been some conceptualisation of the social determinants of oral health, and the factors that operate and interact at multiple levels to influence oral health [6]. However, there has been little translation of the conceptual frameworks into a tangible mechanism to drive decision-making in public dental services. The question remains as to how public oral health services, and the broader public oral health care system, should be reoriented to reduce inequities in oral health using an evidence-based, public health approach.

The aim of this paper is to describe the developmental process for a community-level risk assessment model for oral health to inform the service-delivery approach of Dental Health Services Victoria (DHSV) into the future.

\section{Methods}

\section{Stakeholder consultation}

DHSV is the leading public oral health care provider in Victoria, which is the second most populous state in Australia. In 2013-14, through the Royal Dental Hospital of Melbourne and over 90 community dental clinics,
DHSV provided public oral health services to 411,217 Victorians. However, to enhance the service provided, reduce health inequities, and ensure future activities are appropriately oriented, an evidence-informed, public health approach to planning is to be utilised.

Within DHSV, consultation with a broad range of stakeholders identified that although risk assessment for oral disease is routinely performed at an individuallevel in the dental clinic, to develop a state-wide service and public oral health care system, it is necessary to develop a method of assessing risk of oral disease at a community-level. Such a community risk assessment model would need to acknowledge the multiple factors influencing oral health, as well as the broader social determinants of health. To operate at a service and system-level, the model would also need to be updateable with new data as it becomes available, allow ongoing monitoring and surveillance, have capacity to examine geographical variation in oral health needs, and have utility to inform the optimal allocation of public oral health care services across Victoria.

This project aims to use the best research available to develop a multi-dimensional, community-level risk model which predicts the oral health needs in a given community. The profile would then identify which aspects of the oral health care system should be improved. An overview of the entire process to be undertaken is provided in Fig. 1; this paper reports on the first two steps in the process.

\section{Identification of guiding theoretical frameworks}

An important aspect of the developmental stage was to identify a robust and evidence-based theoretical framework

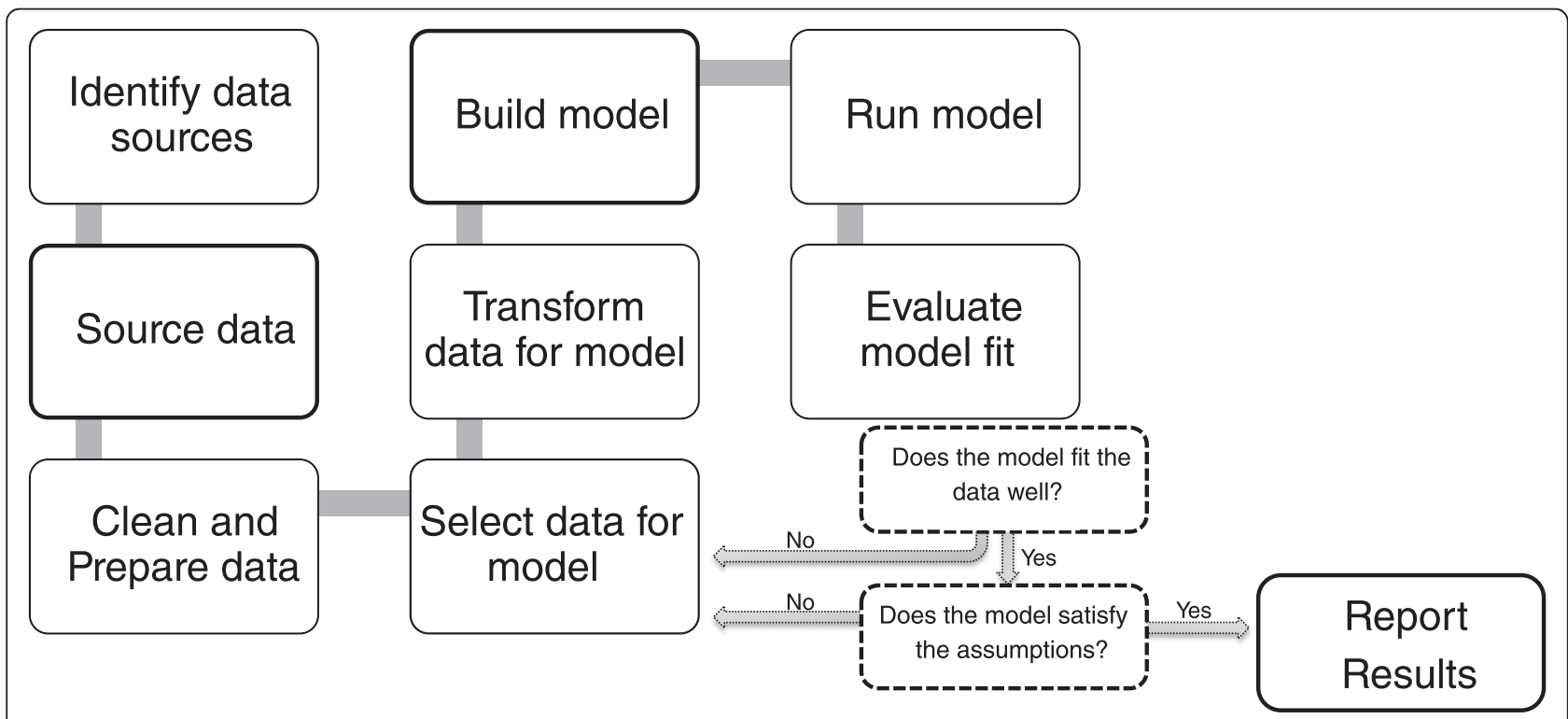

Fig. 1 Flow chart shows steps in model development and testing 
to guide the selection of appropriate indicators and data sources. A comprehensive literature review of published frameworks for risk factors of oral health for children and adults and associated indicators was conducted. The Ovid Medline bibliographic database was searched for relevant articles using the following terms and their combinations: 'frameworks', 'indicators', 'oral health survey,' 'oral health monitoring,' 'epidemiological data,' 'modelling,' 'dental need', and 'population data'. Health Department and other government websites were also searched for documents relating to oral or dental health monitoring.

\section{Identification of available data sources}

The following sources were examined to identify existing Australian data collections for use in the statistical modelling: websites of offices of national statistics; national and state-wide population health surveys (interview and examination); longitudinal cohort studies, and surveillance networks.

There was a particular focus on identifying data sources with participants comparable to (or comprising) the Victorian population and where data was collected as part of health surveys, or as part of clinical or administrative data collections. Oral health examination and interview surveys restricted solely to population groups with special needs were excluded from further consideration.

\section{Selection of indicators and assessment of data quality}

The selection of the indicator set was guided by consistency with underpinning theoretical frameworks, current oral health policy priorities, and scientific validity, reliability and relevance. The Australian Bureau of Statistics (ABS) report 'Measuring Wellbeing: Frameworks for Australian Social Statistics 2001' [7] underlines these basic measurement and analysis issues associated with available data sources in Australia. Inclusion of an indicator in the risk model was also determined after assessing the basic data quality dimensions of: methodological soundness, accessibility, accuracy and reliability $[8,9]$, as described below.

\section{Methodological soundness}

The methodological basis for the statistics follows internationally accepted standards, guidelines, or good practices.

- Concepts and definitions used are in accord with internationally-accepted statistical frameworks.

- The scope is in accordance with internationally accepted standards, guidelines, or good practices

\section{Accessibility}

Data and metadata are easily available and assistance to users is adequate
- Statistics are presented in a clear and understandable manner, forms of dissemination are adequate, and statistics are made available on an impartial basis.

- Up-to-date and pertinent metadata are made available.

\section{Accuracy and reliability}

Source data and statistical techniques are sound and statistical outputs sufficiently portray reality.

- Source data available provide an adequate basis to compile statistics

- Statistical techniques employed conform to sound statistical procedures

\section{Ethics and consent}

As no data was collected for this study no ethics approval or participant consent was sought.

\section{Results}

\section{Identification of frameworks}

Several multi-level frameworks were identified through the searching. The most relevant for this project were: Australia's National Oral Health Plan 2004-2013 [10], The Socio-Ecological Model of Health [2], FisherOwens Model of Child Oral Health [11], WHO model for Oral Health Diseases Surveillance and WHO operational model for an integrated oral health-chronic disease surveillance system [9] and the Framework of Socioeconomic Determinants of Health [12]. The system inputs for our community-level risk assessment model were developed primarily around the WHO frameworks [9, 13, 14] and Australia's National Oral Health Plan 2004-2013 [10]. The framework encompasses two 'Tiers', covering Determinants and Risk factors, and Outcomes. Each tier has a number of domains, each defining a distinct aspect of the tier. The Determinants and Risk factors tier has six domains that bring together a range of factors that affect oral health at individual and population levels: Policy, Health Systems, Sociocultural, Environmental, Behaviours, and Use of Services. The Outcomes tier has two domains that summarise the impact of oral health conditions on individuals: Disease and Quality of Life. The framework is depicted in Fig. 2.

The Australia's National Oral Health Plan 2004-2013 [10] encompasses nineteen process and outcomes indicators for Oral Health under the key domains of the WHO framework [10], which address the main dental diseases: dental caries, periodontal diseases, and oral cancer. 


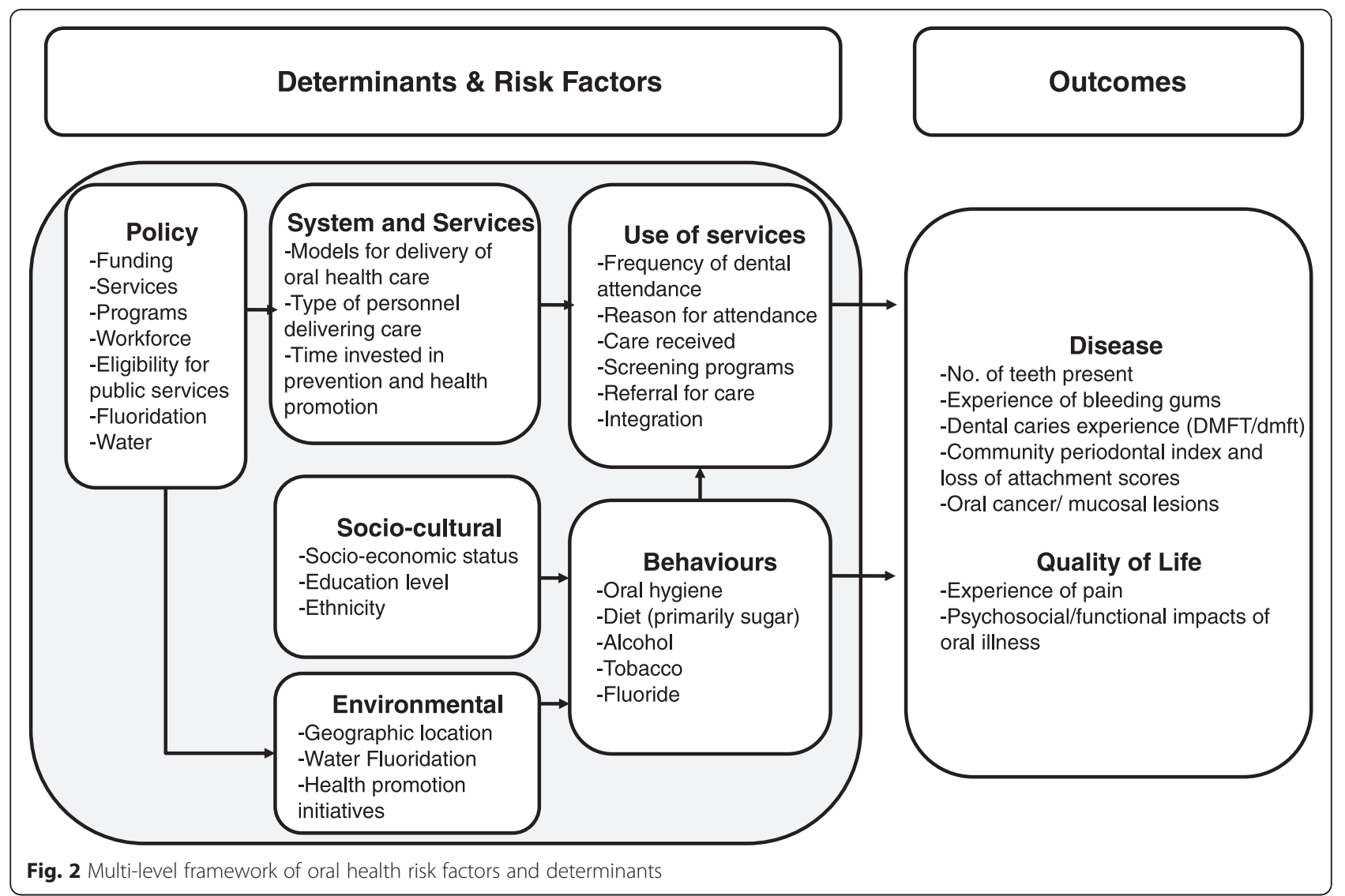

\section{Identification of data sources}

Identified national and state-wide sources with items relevant to oral health status and outcomes indicators, diseases and related risk factors were of two main categories: statistical sources (including surveys and censuses); and administrative sources (including population registries and hospital databases).

A wide range of administrative systems and statistical data collections were compiled by the Australian Institute of Health and Welfare (AIHW) from data supplied by states and territories. Other national sources were: the Australian Bureau of Statistics (ABS), the Department of Human Services (DHS), the Department of Families, Housing, Community Services and Indigenous Affairs (FaHCSIA), and the Australian Institute of Family Studies (AIFS).

Majority of identified state-wide data collections were sourced from the Department of Health and Human Services (DHHS) and Dental Health Services Victoria (DHSV) Other sources were the Cancer Council Victoria (CCV) and the Victorian Department of Education and Training (DET).

The complete list of data sources is summarised in Table 1.

\section{Data quality assessment}

Table 1 summarises the detailed quality assessment of each of the identified data collections. The majority of the surveys provided incidental information on self-reported outcomes, subject to recall and reporting bias. In contrast, national and Victorian population registries and hospital data are collected routinely, based on medical diagnosis, with large samples, thus the information is generally more reliable. However, their capacity to identify differences in disease profile and service utilisation of population subgroups is restricted, due to limited demographics.

National surveys conducted by the Australian Institute of Health and Welfare (AIHW) and Dental Statistics Research Unit (DSRU) used random sampling design and collected incidental information, with the only exception being the National Dental Telephone Interview Survey (NDTIS) repeated every two and a half years. In contrast, data from state-wide surveys are regularly available. Sampling weights were applied in all surveys. In relation to the Census data, several strategies are employed by the ABS to produce high quality data by minimising respondent errors (choosing suitable content, question and form design), processing errors (repairs, coding errors, and validation), partial response and undercount.

Data collections and indicators by framework domain When searching for data sources with items relevant to oral health, and within the domains of the underpinning 
Table 1 Audit of available data sources and assessment of data quality

Data Source
Australian Bureau of Statistics
(ABS)

(ABS)

Department of Human Services (DHS)

Australian Institute of Health and Welfare (AlHW): and AlHW Dental Statistics and Research Unit (DSRU)

Data Set

Census [19]

Population-level data on socioeconomic variables and demographics for a variety of geographic regions

Health Care Card data [20]

National data collected by the government welfare agency 'Centrelink' of adults and children issued a low income 'Health Care Card' which provides access to health care and related benefits, including lower costs.

National Health Workforce Data Set

(NHWDS) [21]

Combines data from the National

Registration and Accreditation Scheme

(NRAS) with data collected from the Dental Workforce Survey (DWS)

Australian Cancer Database (ACD) [18]

Data collection of all primary, malignant

cancers diagnosed in Australia since 1982

The ACD is compiled at the AlHW from

cancer data provided by state and territory

cancer registries through the Australasian

Association of Cancer Registries. These

registries receive information on cancer

diagnoses from a variety of sources such as

hospitals, pathology laboratories,

radiotherapy centres

National Hospital Morbidity Database

(NHMD) [22]

Compiled from data supplied by the State and Territory health authorities. It is an

electronic collection of records for

separations (episodes of care) in public and

private hospitals in Australia. It contains

demographic, administrative and length of

stay data and data on diagnoses of the

patient and medical procedures.

National Survey of Adult Oral Health

(NSAOH) 2004-2006 [15]

A descriptive 'snapshot' of oral health in

the adult population of Australia. Random sample of the general population residing

in all Australian states and territories.

Information is collected using interviews

and standardised dental examinations.

The survey aims to describe levels of ora

Methodological Soundness

Accessibility

Data collected

population

Most recent censu

General Australian population

Routinely collected data available by geographic location

Available data for 2011 and 2012 Access restricted to statistical

dental practitioners

reports by AlHW

Population -based cancer registered patient data in Australia

Representative general population level data for all separations of admitted

patients from all public and private national hospitals

General population 15+ years old Sample size: 2267

Response rate: $44 \%$ of sampled population

Three-stage stratified sampling design

Oral examination restricted to

dentate population

( $N=1181 ; 50 \%$ of eligible)

Data released in AlHW publications and available as interactive data

AlHW can also make available a broad range of cancer statistics subject to scientific/ethical review process

Ongoing collection

Statistical reports by AlHW

Data requests subject to ethics approvals
Incidental data Access restricted to statistical reports by AlHW/DSRU

Accuracy and Reliability

\section{Self-reported data}

Clinical data based on medical diagnosis

Extensive validation of data

Data are checked for valid values, logical and historical consistency

Self-reported oral health status data and clinical data

(dentate population)

Computer assisted interviews, structured questionnaires pilot tested, trained interviewers

Reporting bias

Sampling weights applied
Main sources of error: respondent error (self-enumerated), partial or non-response, processing error Quality management procedures

applied to reduce error

Administrative records data

survey data

In deriving estimates two sources accounted for: ito survey are

Weighted estimates

Clinical data based on medical diagnosis 
Table 1 Audit of available data sources and assessment of data quality (Continued)

disease, perceptions of oral health

and patterns of dental care within a

representative cross-section of adults

across Australia.

National Dental Telephone Interview

Survey (NDTIS) [16]

Telephone survey of a random sample

of the Australian population. Respondents

include users and non-users of denta

services and people eligible and not

eligible for public-funded dental care.

NDTIS collects basic features of oral health

and dental care within the Australian

population, including access to services.

There is no clinical component to the

survey. Survey aims to: collect oral health

and dental care data within the Australian

population; monitor the extent of socia

inequalities within the dental sector;

investigate the underlying reasons behind

dental behaviours, and the consequences

of these behaviours.

Child Dental Health Survey (CDHS) [16]

The Survey monitors the dental health of

children enrolled in school and community

dental services operated by the health

departments or authorities of State and

Territory governments. Survey aims to:

examine the distribution of oral health

status by geographic location and

demographic factors, and the identification

of high-risk groups; and examine changes in

oral health status among children over time

Child Oral Health Study (COHS) 2002-2004 [17] A Survey of parents of children from

South Australia, Victoria, Tasmania and

Queensland

Longitudinal Survey of Dentists' Practice Activity (LSDPA) [23]

A survey of Australian dentists that report

on services provided in private denta

practice. LSDPA data were used to

estimate the mean services and cost of

services for each visit reported in NDTIS.

General population $5+$ years old.

Two-stage stratified sample design.

Sample size varies between

surveys.

Random sample of children

4-15 years old enrolled in the

school dental services

Sample size varies between

surveys

Random sample of children

aged between 5 and 15

Random sample of dentists

from the dental register

surveyed at five-year intervals.

Response rate $70 \%+$ at all five

waves. Sample supplementation

procedure provided

representative cross-sectional

sample
Every $21 / 2$ years

Access Restricted to statistical

reports by AlHW/DSRU

Self-reported survey data

Computer assisted interviews,

structured questionnaires pilot

tested, trained interviewers

Reporting bias

Sampling weights applied

Annual data collection

Data available for Victoria up to

2004

Access restricted to statistical

reports by AlHW/DSRU

Incidental data

Access restricted to statistical

reports by AIHW/DSRU

Five yearly-survey commenced in

1983-84 and completed in 2009-10

Statistical reports by DSRU/AIHW
Routine clinical examination data.

Inter/intra examiner reliability not

assessed

Data cleaning processes to

correct data entry errors and

eliminate duplicate cases

Sampling weights applied
Data weighted to the age, sex
Retrospective reporting

Recall bias

and estimated resident

populations

Mailed structured self-completed

questionnaires

Validation study indicated

representative estimates

Weighted estimates 
Table 1 Audit of available data sources and assessment of data quality (Continued)

\begin{tabular}{|c|c|}
\hline & $\begin{array}{l}\text { National Dental Labour Force Data } \\
\text { Collection (NLFDC) [24] } \\
\text { The National Dental Labour Force Survey } \\
\text { collects information on the demographic } \\
\text { and employment characteristics of dental } \\
\text { practitioners in Australia. Data comes from } \\
\text { the National Registration and Accreditation } \\
\text { Scheme (NRAS) and optional Dental } \\
\text { Workforce Survey }\end{array}$ \\
\hline Cancer Council Victoria (CCV) & $\begin{array}{l}\text { Victorian Cancer Registry (VCR) [34] } \\
\text { Population-based cancer registry receiving } \\
\text { information on cancer diagnoses from } 240 \\
\text { hospitals, } 30 \text { pathology laboratories and } \\
\text { cancer screening services in Victoria }\end{array}$ \\
\hline $\begin{array}{l}\text { Cancer Council Victoria (CCV)/ } \\
\text { Dental Health Service Victoria } \\
\text { (DHSV) }\end{array}$ & $\begin{array}{l}\text { Oral Health Policy Data }[35,36] \\
\text { As part of a larger review of health } \\
\text { promotion policy CCV conducted a review } \\
\text { of oral health municipal promotion plans. } \\
\text { Policy and program data was collected by } \\
\text { CCV for a project in partnership with DHSV } \\
\text { by context analysis of the policies } \\
\text { documents which local governments use } \\
\text { for promoting the health of their } \\
\text { constituents }\end{array}$ \\
\hline \multirow[t]{3}{*}{$\begin{array}{l}\text { Dental Health Services Victoria } \\
\text { (DHSV) }\end{array}$} & $\begin{array}{l}\text { Workforce Dataset [37] } \\
\text { Dataset includes the number and type of } \\
\text { staff at all community dental clinics in } \\
\text { Victoria. }\end{array}$ \\
\hline & $\begin{array}{l}\text { Oral Health Promotion Program [38] } \\
\text { Smiles } 4 \text { Miles is an Oral Health Promotion } \\
\text { Program developed by DHSV and is } \\
\text { targeted at preschoolers. The data } \\
\text { collected is the proportion of kindergartens } \\
\text { in a given community implementing the } \\
\text { program. }\end{array}$ \\
\hline & $\begin{array}{l}\text { Distance to the closest public dental clinic [39] } \\
\text { Distance will be calculated using the } \\
\text { Victorian census collection districts (CCDs) } \\
\text { map. Each CCD will be represented by its } \\
\text { centroids which will be imported into a } \\
\text { statistical software programme. The } \\
\text { distance will be then calculated using the } \\
\text { great circle metric. }\end{array}$ \\
\hline
\end{tabular}

$\begin{array}{ll}\text { All dental practitioners } & \text { Response rates vary between } \\ \text { registered in Australia at the } & \text { years and States } \\ \text { time of the survey } & \text { Significant delays between data } \\ & \text { collection and release of statistics } \\ & \text { Most recent reports in } 2006 \text { and } \\ & 2009\end{array}$

\section{All cancer diagnosis in}

Victorian residents

All local government planning documents across Victoria

Data is collected at clinic leve (all public dental clinics in the State)

Random sample of

kindergartens across Victoria

Online summary statistics (incidence and mortality) by type of cancer, age, sex, year of diagnosis, region of residenceData can also be requested (conditions and limitations apply)

Most available data for 2009 Data provided by CCV
DHSV and agency workforce data readily available monthly.

Data is available from 2009 onwards

Item on-response and survey non-response

Data are weighted to account for the population being examined and imputed for non-response questions

Clinical data based on medical diagnosis

Content Analysis
DHSV workforce calculated from the DHSV payroll database Agency workforce data is selfreported by agencies

Data only represents the number of kindergartens in each region

Distance will be calculated using 'crow file' metric which does not take into consideration the ways which patients visit community clinics 
Table 1 Audit of available data sources and assessment of data quality (Continued)

Department of Families, Housing, Community Services and Indigenous Affairs

(FaHCSIA), Australian Institute of Family Studies (AIFS) Australian Bureau of Statistic (ABS)

Victorian Department of Health and Human Services (DHHS)
Longitudinal Study of Australian Children (LSAC) [25]

Longitudinal study following the

development of children and families from

all Australia. It commenced in 2004 with

two cohorts of children. First wave of dat collection in 2004 with subsequent main waves every two years

The study aimed to investigate the contribution of children's social, economic and cultural environments to their adjustment and wellbeing

Victorian Admitted Episodes Dataset (VAED) [40]

Episodes of care level morbidity data on all admitted patients from Victorian public and private hospitals including

rehabilitation centres, extended care

facilities and day procedure centres. The

VAED also contains demographic,

administrative and length of stay data and

data on diagnoses of the patient and

medical procedures.

Victorian Population Health Survey (VPHS) [27]

The VPHS collects information via

computer assisted telephone interviews

(CATI) at the State, regional and local

government levels on health outcomes,

determinants and behavioural risk factors

of adult Victorians aged 18 years and over

Community Water Fluoridation Program [41]

Water fluoridation is the adjustment of

the natural amount of fluoride in the

water supply to a level recommended for

optimal dental health benefits. Some

communities in regional and rural Victoria

without optimal water receive carefully

controlled amounts of fluoride in their

drinking water

Titanium database [26]

The Titanium database is an electronic patient record management system for public dental agencies. It contains

administrative, demographic, clinical, oral health and risk factors data.

\section{National representative}

Cross-sequential design with

two cohorts $(N=5000$ each):

$0-1$ years and $4-5$ years at the

commencement of the study

Two-stage random clustered

designstratification was used

to ensure proportionate

number of selected children to

the total numbers of children

within each state/territory

Representative general

population level data for all

separations of admitted

patients from all Victorian

public and private hospitals

Representative random sample

of population aged 18+

residing in Victoria

Participation rates vary

between years

Community access to a

fluoridated water supply.

Coverage is classified

geographically by postcode

Eligible population level data only. Eligible is set by government policy and is targeted to populations at highest risk of poor oral health.
Accessible data

Baseline collection in 2004 and

final wave commenced in

2009/2010

Ongoing collection

Data available after request to the department

Annually

Accessible data by financial year

Survey data is weighted between waves questionnaires

Sample weights produced to pant non-response, children's age

Clinical data based on medical diagnosis

Extensive validation of data

Different data collection methods

Computer based self-complete reduce selection bias and partici-

validated scales appropriate to

Data are checked for valid values, logical and historical consistency

\section{Accessible data}

Routinely collected

Accessible by DHSV staff for all

public dental agencies in Victoria
Clinical examination data

User data entry error

Most common identified areas of inaccuracy include:

- Capture of DMF score where dental chart has not been

performed or is incomplete

Un-erupted teeth incorrectly recorded as missing inflating the M component of the DMFT 
Table 1 Audit of available data sources and assessment of data quality (Continued)

scoreldentification of teeth missfor reasons not due to dental decay

Victorian Department of

Education and Training (DET)
Victorian Child Health and Wellbeing Survey (VCHWS) [28]

State-wide survey of children $0-13$ years of age. The survey is conducted to examine

the health of Victorian children and to

describe the general health levels and high

risk groups. Data is collected on health

outcomes, socioeconomic determinants,

and behavioural risk factors

School Entrant Health Questionnaire

(SEHQ) [29]

Population level

cross-sectional survey

$N=5000$, response rate: $86.6 \%$

Repeated every three years

Parental self-reported data

Interviewer training

Monitoring and call-back valid-

ation

Structured questionnaires

Existing scales with proven reliability and validity

Population-based level crosssectional survey of all children

entering primary schools

Repeated annually
Parental self-reported data Structured, piloted questionnaireSchool nurse clinical assessment

Existing scales with proven

reliability and validity

children are in their first year of schooling.

The SEHQ contains a range of questions

focusing on family demographics, child

health and development. The questionnaire school Nursing program 
frameworks, twelve national and eight state-wide data collections were identified.

Oral health status and outcomes indicators were identified in a variety of national data collections including: i) population based surveys: the National Survey of Adult Oral Health (NSAOH) [15], the National Dental Telephone Interview Survey (NDTIS) [16] the Child Dental Health Survey (CDHS) [17], and Child Oral Health Study (COHS) 2002-2004 [17]; ii) administrative systems : the Australian Cancer Database (ACD) [18].

Indicators covering the risk factors and determinants domains were identified in the following national collections: Census of Population and Housing survey [19], Health Care Card data [20], National Health Workforce Data Set (NHWDS) [21],National Hospital Morbidity Database(NHMD) [22],Longitudinal Survey of Dentists' Practice Activity (LSDPA) [23], National Dental Labour Force Data Collection (NLFDC) [24], and Longitudinal Study of Australian Children (LSAC) [25].

The main state-wide hospital database with oral health status, outcomes, and risk factors items was Titanium [26], a patient record system for Victorian public dental agencies. Data collections with behavioural risk factors were primarily population surveys including theVictorian Population Health Survey (VPHS) [27], the Victorian Child Health and Wellbeing Survey (VCHWS) [28], and the School Entrant Health Questionnaire (SEHQ) [29]. The complete list of identified data collections and indicators is summarised in Table 1.

A total of forty-eight evidence-based indicators of interest were selected across all domains. Majority of determinants and risk factors indicators were within the domains of: i) use of services: dental attendance, reason for attendance, dental general anesthetics (DGA), early detection, preventive care, emergency care and recall period for children; and ii) systems and services: financing care, access to services, waiting time, and organisational practices. Selected oral health conditions and quality of life indicators for measuring outcomes were: caries severity and prevalence, untreated tooth decay, fissure sealants, functional and non-functional dentition, periodontal disease severity, oral cancer mucosal lesions, experience of pain, and psychosocial and functional impacts of oral illness. The list of all selected indicators of interest against the framework domains is summarised in Table 2.

A selection of twenty indicators to be included in the model is shown in Table 3, along with the associated data sources. All except for two (caries experience and functional dentition) were determinants and risk factors.

The selection was based on: alignment with the theoretical model, data/item availability and currency, suitability (similarity) of sample population, potential for use in a mixed data-source statistical model. The number of variables from each dataset that have been incorporated into the model varies. Available data is collected at the levels of Local Government Area (LGA), postcode, community dental agency and census collection district (CCD) levels, and where necessary will be disaggregated or aggregated and used at suburb/postcode level to minimise averaging errors. Most recent available datasets for each data collection will be sourced and used.

\section{Discussion}

Identification of communities at high risk of developing dental disease across multiple dimensions enables the appropriate allocation of public dental services and resources, as a first step to reducing oral health inequalities across the population. In the current study, we have identified a guiding framework and multiple data sources to develop a risk assessment model to enable reorientation of public oral health care services. We have also catalogued available oral health-related data sources to provide a resource for public oral health researchers, policy makers and service providers.

An appropriately directed public oral health service must be able to regularly monitor the costs and clinical effectiveness of the interventions provided, as well as population disease and health inequalities. This requires a shift in the focus and reporting systems from an emphasis on outputs to outcomes. It also requires quality data collections and robust indicator sets. Our research identified numerous sources with items relevant to oral status and outcomes indicators, diseases and related risk factors. These sources were of two main categories: statistical sources, including surveys and censuses, and administrative sources, such as population registries and hospital databases.

The majority of the survey data collected provided incidental information on self-reported outcomes, and were subject to recall and reporting bias. In contrast, population registries and hospital data are based on medical diagnosis thus the information is generally more reliable; however, their capacity to identify differences in disease profile or service utilisation by population subgroups is restricted, due to only limited demographic data being collected. Further, these data collections only include members of the population who utilise such services, and generally do not include individuals who use alternative, privately run services. However, the data sources identified were generally stand-alone and not articulated in with other data collections or monitoring systems. Exploring options for integration of datasets in real time is important to enable more integrated health services to be delivered. Further, improving the data system, so that data linkage at an individual level can occur, will enhance future use of existing data assets, providing a quantum leap in our ability to explore causal pathways 
Table 2 Summary of identified indicators of interest and available data sources for the Victorian population by framework domain

\begin{tabular}{|c|c|c|c|}
\hline Domain & Element & Definition of Indicator & Data sources/sets \\
\hline \multicolumn{4}{|c|}{ Determinants \& Risk Factors } \\
\hline \multirow[t]{3}{*}{ Policy } & Local government & $\begin{array}{l}\text { Proportion of Local Government areas with } \\
\text { policies addressing oral health risk factors }\end{array}$ & $\begin{array}{l}\text { CCV \& DHSV/Oral Health } \\
\text { Policy data }\end{array}$ \\
\hline & $\begin{array}{l}\text { Setting: Schools and } \\
\text { Kindergartens }\end{array}$ & $\begin{array}{l}\text { Proportion of kinder gardens/schools with } \\
\text { policies addressing oral health risk factors }\end{array}$ & $\begin{array}{l}\text { DHSV/Smiles for Miles Oral } \\
\text { Health Promotion Program }\end{array}$ \\
\hline & Health service: Hospitals & $\begin{array}{l}\text { Proportion of hospitals with policies } \\
\text { addressing oral health risk factors }\end{array}$ & $\begin{array}{l}\text { CCV \& DHSV/Oral Health } \\
\text { Promotion Policy Data }\end{array}$ \\
\hline \multirow[t]{6}{*}{ System and Services } & Financing care & $\begin{array}{l}\text { Proportion of population eligible for free or } \\
\text { low cost public dental services }\end{array}$ & ABS \& DHS/Centrelink \\
\hline & Access to services & $\begin{array}{l}\text { Distance to closest public clinic from } \\
\text { census collection district centroid }\end{array}$ & DHSV/project specific \\
\hline & & $\begin{array}{l}\text { Practising dentist per } 100,000 \text { population } \\
\text { by remoteness category of main practise }\end{array}$ & $\begin{array}{l}\text { AlHW DSRU/National } \\
\text { Dental } \\
\text { Labour Force Collection } \\
\text { AlHW/NHWDS } \\
\text { DHSV/Workforce }\end{array}$ \\
\hline & & $\begin{array}{l}\text { Proportion of children in the area who } \\
\text { access the public system }\end{array}$ & DHHS/Titanium \\
\hline & Waiting period & $\begin{array}{l}\text { Waiting times (average period in months) } \\
\text { Proportion of population seen within the } \\
\text { recommended waiting times }\end{array}$ & DHHS/Titanium \\
\hline & $\begin{array}{l}\text { Organisational Practices: Recall } \\
\text { period for children }\end{array}$ & $\begin{array}{l}\text { Recall period for children (average period } \\
\text { in months) }\end{array}$ & DHHS/Titanium \\
\hline \multirow[t]{2}{*}{ Environmental } & Fluoridated water supply & $\begin{array}{l}\text { Proportion of population with access to } \\
\text { fluoridated water }\end{array}$ & DHHS \\
\hline & Geographical location & $\begin{array}{l}\text { Australian Standard Geographic } \\
\text { Classification of remoteness }\end{array}$ & ABS/Census \\
\hline \multirow[t]{6}{*}{ Socio-cultural } & Socio-economic status & $\begin{array}{l}\text { Socio Economic Index For Areas } \\
\text { (SEIFA)-Index of Disadvantage }\end{array}$ & ABS/Census \\
\hline & Education level & $\begin{array}{l}\text { Proportion of adult population who did } \\
\text { not complete secondary school }\end{array}$ & $\begin{array}{l}\text { ABS/Census } \\
\text { VCHWS }\end{array}$ \\
\hline & Ethnicity/cultural group & $\begin{array}{l}\text { Proportion of adult population who do not } \\
\text { speak English at home }\end{array}$ & ABS/Census \\
\hline & Household income & Health card holder status & ABS/Census \\
\hline & Migrant Status & $\begin{array}{l}\text { Proportion of population (adults and } \\
\text { children) who are migrants }\end{array}$ & ABS/Census \\
\hline & Indigenous Status & $\begin{array}{l}\text { Proportion of population who are } \\
\text { Indigenous }\end{array}$ & ABS/Census \\
\hline \multirow[t]{7}{*}{ Use of services } & Dental attendance & $\begin{array}{l}\text { Proportion of population receiving timely } \\
\text { dental care ( }<12 \text { months) }\end{array}$ & $\begin{array}{l}\text { DHHS/Titanium } \\
\text { DET/NCHWS } \\
\text { AlHW DSRU/NSAOH, NDTIS }\end{array}$ \\
\hline & Reason for attendance & $\begin{array}{l}\text { Proportion of population attending for } \\
\text { treatment vs check-up }\end{array}$ & $\begin{array}{l}\text { AlHW DSRU/NSAOH, NDTIS } \\
\text { DHHS/Titanium }\end{array}$ \\
\hline & $\begin{array}{l}\text { Dental General Anaesthetics } \\
\text { (DGA) }\end{array}$ & $\begin{array}{l}\text { Child DGA rates per } 100,000 \text { for removal } \\
\text { and/or restoration }\end{array}$ & DHHS/NAED, AlHW/NHMD \\
\hline & Early detection/preventative & $\begin{array}{l}\text { Proportion of population treated for early } \\
\text { disease }\end{array}$ & $\begin{array}{l}\text { DHHS/Titanium } \\
\text { AlHW DSRU/NSAOH }\end{array}$ \\
\hline & Care received & $\begin{array}{l}\text { Proportion of population who received } \\
\text { preventive care }\end{array}$ & $\begin{array}{l}\text { DHHS/Titanium } \\
\text { AlHWDSRU/NSAOH }\end{array}$ \\
\hline & & $\begin{array}{l}\text { Courses of care by provider level: general/ } \\
\text { emergency/specialist }\end{array}$ & DHHS/Titanium \\
\hline & Emergency care & $\begin{array}{l}\text { Ratio of emergency to general oral care } \\
\text { provided by public oral health care service }\end{array}$ & DHHS/Titanium \\
\hline
\end{tabular}


Table 2 Summary of identified indicators of interest and available data sources for the Victorian population by framework domain (Continued)

Recall period for children

Behaviours

Oral hygiene practises

Tap water

Diet

Alcohol consumption

Tobacco

Outcomes:

Disease Children

Dental caries severity

Dental caries prevalence

Untreated dental caries

Dental Sealants

Oral health status

\section{Adults}

Dental caries severity

Dental caries prevalence

Untreated dental caries

Non-Functional dentition

Functional dentition

Periodontal Disease Severity

Oral Cancer mucosal lesions

Quality of Life

Experience of pain

Psychosocial and functional impacts of oral illness
Recall period for children (average period in months at when children re-attend the public oral health service)

Proportion of children and adolescents who brush their teeth twice a day

Proportion of population who regularly drink tap water

Proportion of population who regularly drink sweet drinks

Proportion of adults who drink alcohol at levels beyond that considered safe in the long term

Proportion of population who smoke tobacco

Mean number of decayed, missing and filled primary (dmft/s) and permanent (DMFT/S) teeth/surfaces with caries experience

Proportion of children experiencing dental caries (dmft/s >0 and DMFT/S >0)

Proportion of children with $1+$ untreated dentine decayed teeth

Proportion of children with dental sealants

Proportion of children whose parents have concerns about their child's oral health at school entry

Mean number of decayed, missing and filled permanent (DMFT/S) teeth/surfaces with caries experience

Proportion of population experiencing dental caries (DMFT/S $>0$ )

Proportion of population with 1+ untreated dentine decayed teeth

Proportion of edentulous adults

Proportion of population with $21+$ natural teeth

Proportion of dentate adults with periodontal diseases -severity and extent-

Annual incidence rates of oral cancer (cancer of the lip, oral cavity, pharynx) per 100,000 population

Proportion of population who experience tooth ache regularly

Proportion of adult population often or very often felt uncomfortable with the appearance of their teeth or dentures
DHHS/Titanium

ETNCHWS AlHW DSRU/COHS

DETNCHWS

DHHSNPHS

FaHCSIA \& ABS/LSAC

DETNCHWS

DHHSNPHS

DHHSNPHS

AlHW DSRU/CDHS

DHHS/Titanium

AlHWDSRU/CDHS DHHS/Titanium

AlHW DSRU/CDHS DHHS/Titanium

AlHW DSRU/CDHS DHHS/Titanium

DET/SEHQ

AlHW DSRU/NSAOH DHHS/Titanium

AlHW DSRU/NSAOH DHHS/Titanium

AIHW DSRU/NSAOH DHHS/Titanium

AlHW DSRU/NSAOH DHHS/Titanium

AlHW DSRU/NSAOH/NDTIS DHHS/Titanium

AlHW DSRU/NSAOH

DHHS/Titanium

CCVNCR, AlHW/ACD

AIHW DSRU/NDTIS, NSAOH

AIHW DSRU/NDTIS, NSAOH

Socio Economic Index For Areas (SEIFA): Index developed by ABS that ranks areas in Australia according to relative socioeconomic advantage/disadvantage

and long-term impacts through prospective, longitudinal data sets which are also large and representative. This need, and the potential of this powerful approach for improving oral health, has been recognised by others [30].
Despite the limitations with the data collections, it is clear that there is a wealth of existing survey and routinely collected data that can be better utilised to inform decisions in relation to oral health policy, programs and 
Table 3 Summary of indicators to be included in the risk model and associated data sources

\begin{tabular}{|c|c|c|}
\hline Domain & Indicator & Data source/Data Set \\
\hline \multicolumn{3}{|c|}{ Determinants \& Risk Factors } \\
\hline Policy & $\begin{array}{l}\text { Local government municipal health plan analysis } \\
\text { Proportion of children's services implementing oral health } \\
\text { promotion programs }\end{array}$ & CCV \& DHSV \\
\hline \multirow[t]{3}{*}{ Systems and Services } & Distance to closest public clinic & DHSV/Project specific \\
\hline & Average time on waiting list & DHHS/Titanium \\
\hline & Average period of recall time & DHHS/Titanium \\
\hline \multirow[t]{4}{*}{ Socio-cultural } & $\begin{array}{l}\text { SEIFA } \\
\text { Proportion who are health care card holders }\end{array}$ & $\begin{array}{l}\text { ABS/Census } \\
\text { DHS/Centrelink }\end{array}$ \\
\hline & Proportion who did not complete secondary school & ABS/Census \\
\hline & Proportion non-English speaking at home & ABS/Census \\
\hline & $\begin{array}{l}\text { Proportion of migrants } \\
\text { Proportion of population who are Indigenous }\end{array}$ & $\begin{array}{l}\text { ABS/Census } \\
\text { ABS/Census }\end{array}$ \\
\hline \multirow[t]{2}{*}{ Environmental } & Proportion without access to fluoridated water & DHHS \\
\hline & Remoteness & ABS/Census \\
\hline \multirow[t]{4}{*}{ Behaviours } & $\begin{array}{l}\text { Proportion of adult ( } 18+\text { years old) and child } \\
(0-13 \text { years old) population who brush their teeth twice a day }\end{array}$ & $\begin{array}{l}\text { DHHSNPHS } \\
\text { DETNCHWS }\end{array}$ \\
\hline & $\begin{array}{l}\text { Proportion of adult ( } 18+\text { years old) and child } \\
\text { ( } 0-13 \text { years old) population who regularly drink tap water }\end{array}$ & $\begin{array}{l}\text { DHHSNPHS } \\
\text { DETNCHWS }\end{array}$ \\
\hline & $\begin{array}{l}\text { Proportion of child population ( } 0-13 \text { years old) who } \\
\text { regularly drink sweet drinks }\end{array}$ & DETNCHWS \\
\hline & $\begin{array}{l}\text { Proportion of people who are at long term risk from drinking } \\
\text { alcohol ( } 18+\text { years old) } \\
\text { Proportion of population who smoke ( } 15+\text { years old })\end{array}$ & DHHS/NPHS \\
\hline Use of services & $\begin{array}{l}\text { General Anaesthesia (GA) rates } \\
\text { Number of courses of care by provider level in each } \\
\text { category (general/emergency/specialist) }\end{array}$ & $\begin{array}{l}\text { DHHSNAED } \\
\text { DHHS/Titanium }\end{array}$ \\
\hline \multicolumn{3}{|l|}{ Outcomes: } \\
\hline Disease & Dental caries severity & DHHS/Titanium \\
\hline Quality of Life & Functional dentition & DHHS/Titanium \\
\hline
\end{tabular}

AIHW Australian Institute of Health and Welfare

DHSV Dental Health Services Victoria

SEIFA Socio-Economic Index for Areas (index of disadvantage)

VPHS Victorian Population Health Survey

VCHWS Victorian Child health and Wellbeing Survey

VAED Victorian Admitted Episodes Dataset

service delivery. Importantly, we have identified that the available data is not solely located within the health sector which highlights the need for collaborations and partnerships that are cross-sectoral. In this research we have also moved beyond analysing individual items or indicators in data sets, and have identified a robust framework that provides a guiding structure for assembling the available data in a coherent and useful way. This enables us to paint a picture of the risk factors for poor oral health that are operating in the population at a given point in time. Importantly, it is also apparent from this study that no single data collection contains all the necessary information for an integrated oral health-chronic disease surveillance system, as recommended by WHO [9]. Many of the difficulties of using data from multiple and varied sources have previously been identified [31, 32], however the focus has been largely on the appropriate statistical methods to use to provide robust results. There has been little discussion of the practicalities of sourcing, assessing, cleaning, and harmonising data collected at multiple levels such as the individual, family, community and area, although the importance of this for public health has been identified [33].

Data collection is a resource-intensive exercise, and in the absence of a routine oral health monitoring or surveillance system in Australia, a community risk assessment model presents the opportunity to explore patterns and clusters of multiple risk factors in the population based on geographic area. The Model will also enable the examination of multi-dimensional impacts of past and future strategies, interventions and policies on populations, services and systems. This information can then inform health service planning and 
the approaches to addressing common risk factors and preventing chronic diseases. In the context of limited resources for research and evaluation, having a mechanism to examine population impacts of innovative public health strategies is critical.

\section{Limitations}

This study is limited to the information available at the time of searching. This relates to searching for both frameworks and available datasets. Not all of the data required in the framework could be sourced. It is possible that additional sources are now available. The ability to use the identified data sources in the statistical modelling has not been tested in this phase of the study, which is a further limitation, although this will be the focus of the next stage of the project. We were also unable to find directly comparable studies with which to compare our findings.

\section{Next steps}

The project will continue to progress through the remaining stages shown in Fig. 1. This involves harmonising and combining data sources that were initially collected for different purposes, in different geographical areas, from different subpopulations and/or at different times. Statistical models that have utilised mixed data sources will be scrutinised to inform the best methods to use in the community-level risk assessment model for oral health. Initially the data will be used to investigate the statistical relationship between risk factors and oral health outcomes, to confirm the predictive value of the selected indicators. After exploring and describing the relationships between indicators and outcomes the statistical models of community-level risk will be developed, appropriately including a selection of the indicators of risk. The model deliberately contains both risk and protective factors, as these factors occur concurrently at the community level. This next stage of the project will determine the relative importance of the different influences and provide important, policy-relevant findings. The oral health risk model will be developed for all geographic areas in Victoria and will be used by DHSV to guide resource allocation for public dental services. Routinely collected clinical data will also be monitored to evaluate the effect of utilising a population health planning model for public oral health services on disparities in oral disease across the population.

\section{Conclusions}

The community-level risk assessment model is being developed as a response to a need to transform the approach to reducing disparities in oral health, and reorient the allocation of public oral health services in contemporary Australia. Given our growing knowledge of the multi-dimensional influences of oral health, and our ability to prevent or arrest the disease with appropriate strategies, there is a clear need to move from a traditional approach to a more meaningful, responsive and effective model for providing public oral health services.

\begin{abstract}
Abbreviations
ABS: Australian bureau of statistics; ACD: Australian cancer database; AIFS: Australian institute of family studies; AlHW: Australian institute of health and welfare; CCV: cancer council victoria; CDHS: child dental health survey; COHS: child oral health study; DET: department of education and training; DHHS: department of health and human services; DHS: Australian government department of human services; DHSV: dental health services victoria; DSRU: dental statistics and research unit, aihw; FaHCSIA: department of families, housing, community services and indigenous affairs;

LSDPA: longitudinal survey of dentists' practice activity; LSAC: Iongitudinal study of australian children; NRASL: national registration and accreditation scheme; NDTIS: national dental telephone interview survey; NLFDC: national dental labour force data collections; NHWDS: national health workforce data set; NHMD: national hospital morbidity database; NHWDS: national health workforce data set; NSAOH: national survey of adult oral health; SEIFA: socioeconomic index for areas (index of disadvantage); SEHQ: school entrant health questionnaire; VAED: victorian admitted episodes dataset; VCR: victorian cancer registry; VCHWS: victorian child health and wellbeing survey; VPHS: victorian population health survey.
\end{abstract}

\section{Competing interests}

The authors declare that they have no competing interests.

\section{Authors' contributions}

AdeS conceptualised the study and oversaw the project and prepared draft versions of the paper. PG was involved in developing the design of the study, developing the methods, locating and reviewing data sources, performing the quality assessment, and writing the manuscript. LC was involved in the method development, locating and reviewing data sources, and drafting the manuscript. DC provided input into the design of the study, had significant input into interpretation of the findings and assisted with writing of the manuscript. All authors read and approved the final manuscript.

\section{Acknowledgments}

Thank you to Rhydwyn McGuire and Martin Whelan for assistance with data sourcing and data management. We also acknowledge the contributions of Jacqueline Martin-Kerry, Holly Brown and Michelle Chatelier for assistance with formatting the manuscript.

\section{Author details}

${ }^{1}$ Centre for Applied Oral Health Research, Dental Health Services Victoria, 720 Swanston Street, Carlton 3053, Australia. ${ }^{2}$ Melbourne Dental School, University of Melbourne, Carlton 3053, Australia. ${ }^{3}$ Infectious Diseases Division, Department of Internal Medicine I, University Hospital Tübingen,

Otfried-Müller-Street, Tübingen 72076, Germany. ${ }^{4}$ Jack Brockhoff Child Health and Wellbeing Program, Centre for Health Equity, The Melbourne School of Population and Global Health, University of Melbourne, Bouverie Street, Carlton 3053, Australia. ${ }^{5}$ Dental Health Services Victoria, 720 Swanston Street, Carlton 3053, Australia.

Received: 26 November 2015 Accepted: 16 March 2016

Published online: 31 March 2016

\section{References}

1. Whitehead M. A typology of actions to tackle social inequalities in health. Journal Epidemiology and Comminity Health. 2007;61:473-8.

2. McLeroy KR et al. An ecological perspective on health promotion programs. Health Educ Q. 1988;15(4):351-77.

3. Bronfenbrenner U. The Ecology of Human Development. London: Harvard University Press; 1979.

4. Bronfenbrenner $\mathrm{U}$. Ecology of the familiy as a context for human development: Research perspectives. Dev Psychol. 1986;22(6):723-42.

5. Moore SN, Murphy S, Moore L. Health improvement, nutritional behaviour and the role of school meals: the usefulness of a socio-ecological 
perspective to inform policy design, implementation and evaluation. Critical Public Health. 2011;21(4):441-54.

6. Petersen PE. The World Oral Health Report 2003. Continuous improvement of oral health in the 21st century - the approach of the WHO Global Oral Health Programme. Available at http://www.who.int/oral_health/media/en/ orh_report03_en.pdf.

7. Australian Bureau of Statistics. Measuring Wellbeing: Frameworks for Australian Social Statistics. 200131 July 2006 [cited 201524 April 2015]; Available from: http://www.abs.gov.au/ausstats/abs@.nsf/0/ 44AD1E3F6E6F27A2CA25713F0014E6DA?opendocument.

8. International Monetary Fund. Data Quality Assessment Framework. 2006

9. Petersen PE et al. Oral health information systems-towards measuring progress in oral health promotion and disease prevention. Bulletin World Health Organisation. 2005;9(83):686-93.

10. National Advisory Committee on Oral Health. Australia's National Oral Health Plan. 2004.

11. Fisher-Owens SA et al. Influences on children's oral health: a conceptual model. Pediatrics. 2007;120(3):510-20.

12. Turrell $\mathrm{G}$ et al. Socioeconomic determinants of health: towards a national research program and a policy and intervention agenda. Canberra: Queensland University of Technology; 1999.

13. Wilkinson R, Marmot M. Social Determinants of Health. The solid facts. Denmark: World Health Organisation; 2003.

14. World Health Organisation. Social Determinants 2015 [cited 201128 November 2011]; Available from: http://www.euro.who.int/en/health-topics/ health-determinants/social-determinants/social-determinants.

15. AlHW Dental Statistics and Research Unit (2007) Australia's dental generations: the National Survey of Adult Oral health 2004-06. 292

16. Australian Institute of Health and Welfare. Dental and Oral Health Publications 2015 [cited 201414 October 2014]; Available from: http://www. aihw.gov.au/dental-and-oral-health-publications/.

17. Armfield, J.M. and A.J. Spencer. Dental health behaviours among children 2002-2004: the use of fluoride toothpaste, fluoride tablets and drops, and fluoride mouthrinse 2012 [cited 201415 October 2014]; Available from: http://www.aihw.gov.au/publication-detail/?id=10737421052

18. Australian Institute of Health and Welfare. Australian Cancer Database (ACD) 2015 [cited 201414 October 2014]; Available from: http://www.aihw.gov.au/ australian-cancer-database/.

19. Australian Bureau of Statistics. Census. 201511 March 2015 [cited 201420 October 2014]; Available from: http://www.abs.gov.au/census

20. Australian Government Department of Human Services. Data.gov.au. 2014.

21. Australian Institute of Health and Welfare. National Health Workforce Data Set. 2014 [cited 201414 October 2014]; Available from: http://www.aihw. gov.au.

22. Australian Institute of Health and Welfare. National Hospital Morbidity Database (NHMD). 2015 [cited 201414 October 2014]; Available from: http://www.aihw.gov.au/hospitals-data/national-hospital-morbiditydatabase/.

23. Australian Institute of Health and Welfare. Age and the costs of dental care in Research Report Series. Australia: Australian Institute of Health and Welfare Canberra; 2010.

24. Chrisopoulos, S. and T. Nguyen. Trends in the Australian Dental labour Force, 2000 to 2009: dental labour force collection, 2009. 2012 [cited 201415 October 2014]; Available from: http://www.aihw.gov.au/publication-detail/ ?id=10737421917

25. Australian Institute of Family Studies. Longitudinal Study of Australian Children (LSAC) 2010 [cited 201420 October 2014]; Available from: http://www.aifs.gov.au/institute/media/mediabackgrounders/lsac.html.

26. Dental Health Services Victoria. Titanium Database 2014 [cited 201414 October 2014]; Available from: https://www.dhsv.org.au

27. Victorian Department of Health and Human Services. Victorian Population Health Survey (VPHS). 2014 [cited 201420 October 2014]; Available from: http://docs.health.vic.gov.au/docs/doc/Nictorian-population-health-survey2014---information-brochure

28. Victorian Department of Education and Training. Victorian Child Health and Wellbeing Survey (VCHWS) 2014 [cited 201414 October 2014]; Available from: http://www.education.vic.gov.au/about/research/pages/newdata.aspx.

29. Victorian Department of Education and Training. School Entrant Health Questionnaire (SEHQ). 2014 [cited 201414 October 2014]; Available from: http://www.education.vic.gov.au/about/research/pages/ reportdatahealth.aspx.
30. Slack-Smith L. How population-level data linkage might impact on dental research. Community Dentistry Oral Epidemiology. 2012;40:90-4.

31. De Angelis $D$ et al. Four key challenges in infectious disease modelling using data from multiple sources. Epidemics. 2015;10:83-7.

32. Samsa G, Hu G, Root M. Combining Information From Multiple Data Sources to Create Multivariable Risk Models: Illustration and Preliminary Assessment of a New Method. Journal Biomedicine and Biotechnology. 2005;2005(2): $113-23$.

33. Murray CJL, Lopez AD. Measuring the Global Burden of Disease. New England Journal Medicine. 2013;369(5):448-57.

34. Cancer Council Victoria. Victorian Cancer Registry 201422 December 2014 [cited 201421 October 2014]; Available from: http://www.cancervic.org.au/ research/registry-statistics/vcr.

35. Cancer Council Victoria and Dental Health Services Victoria. Oral Health Policy Data 2014 [cited 201415 October 2014]; Available from: https://www. dhsv.org.au.

36. Heilbrunn-Lang AY et al. Reviewing public policy for promoting population oral health in Victoria, Australia (2007-12). 2015. Australian Health Review.

37. Dental Health Services Victoria. Workforce Dataset. 2014 [cited 201416 October 2014]; Available from: https://www.dhsv.org.au.

38. Dental Health Services Victoria. Smiles 4 Miles. 2014 [cited 201417 October 2014]; Available from: https://www.dhsv.org.au/oral-health-programs/ smiles4miles.

39. Dental Health Services Victoria. Victorian Census Collection Districts 2014 [cited 201420 October 2014]; Available from: https://www.dhsv.org.au/

40. Victorian Department of Health and Human Services. Victorian Admitted Episodes Dataset (VAED). 2014 [cited 201415 October 2014]; Available from: http://www.health.vic.gov.au/hdss/vaed.

41. Victorian Department of Health and Human Services. Water Fluoridation Program. Available from: https://www2.health.vic.gov.au/public-health/ water/water-fluoridation

\section{Submit your next manuscript to BioMed Central and we will help you at every step:}

- We accept pre-submission inquiries

- Our selector tool helps you to find the most relevant journal

- We provide round the clock customer support

- Convenient online submission

- Thorough peer review

- Inclusion in PubMed and all major indexing services

- Maximum visibility for your research

Submit your manuscript at www.biomedcentral.com/submit
) Biomed Central 